\title{
Transmission Performance Investigation of IR-UWB Signals over Existing optical fiber Transmission link
}

\author{
J. E. KADUM, R. S. FYATH \\ M.Sc Researcher, College of Engineering, Alnahrain University, Baghdad, Iraq \\ jaffar.emad@yahoo.com \\ Professor, College of Engineering, Alnahrain University, Baghdad, Iraq \\ rsfyath@yahoo.com
}

\section{ABSTRACT}

Recently there is increasing interest in using optical fiber links to distribute impulse radio-ultrawideband (IR-UWB) signals in order to increase the coverage area. This paper investigates the transmission performance of these signals over existing fiber links and addresses the possibility of increasing the coverage area beyond $30 \mathrm{~km}$. The transmission link consists of a single-mode fiber, dispersion compensating fiber (DCF) and, optical amplifiers. Simulation results are presented using Optisystem (version 13.0) software package for both Gaussian monocycle and $5^{\text {th }}$-order derivative Gaussian systems, each operating with ON-OFF keying (OOK) and biphase modulation (BPM) formats. The results reveal that extending the coverage area for $625 \mathrm{Mb} / \mathrm{s}$ UWB signal toward $100 \mathrm{~km}$ is possible for the UWB signals and modulation formats adopted in this study.

\section{Indexing terms/Keywords}

IR-UWB -over- fiber; radio-over-fiber.

\section{Academic Discipline And Sub-Disciplines}

Optical Communications

\section{SUBJECT CLASSIFICATION}

UWB-over-Fiber

\section{TYPE (METHOD/APPROACH)}

Analysis and simulation

\section{Council for Innovative Research}

Peer Review Research Publishing System

\section{Journal: INTERNATIONAL JOURNAL OF COMPUTERS \& TECHNOLOGY}

Vol. 14, No. 1

www.ijctonline.com, editorijctonline@gmail.com 


\section{1- INTRODUCTION}

Ultra wide band (UWB) communication is an emerging technology that uses very low energy levels for transmitting data over a wide portion of the radio spectrum [1,2]. This technology has attracted increasing interest in recent years for short range high speed wireless communication over high bandwidth within unlicensed spectrum $(3.1-10.6 \mathrm{GHz})$ as specified by the Federal Communicating Comission (FCC) $[3,4]$. The UWB-based communication is characterized by low interference to existing wireless systems due to its very low signal-to-noise ratio (SNR) operation and extremely low radiation power spectral density (PSD) (below $-41.3 \mathrm{dBm} / \mathrm{MHz}$ ) [3,5]. Modern UWB communication systems may be realized in the impulse form leading to the concept of impulse radio (IR) UWB transmission. Here, information is carried in a set of narrow pulses of electromagnetic energy where the bandwidth is approximately proportional to the pulse width $[4,6]$. Different applications based on IR-UWB communication have been emerged such as wireless body sensor networks [5], interchip data transmission [7], high resolution ranging system [8,9], wireless sensor network synchronization [10], and in-building network applications [1]. These applications are driven by the progress reported in the design of IR-UWB transmitters capable of shaping the power spectrum of the UWB signal to mitigate mutual interference $[11,12]$ and receivers with narrow band interference mitigation capabilities [13,14].

However, one fundamental limitation of IR-UWB technology is the extremely low power density which restricts the coverage distance to a few or tens of meters. One solution to extend the transmission distance is to take advantages of optical fiber, such as low loss, large bandwidth and immunity to electromagnetic interference $[4,15]$. This leads to new communication technology called UWB-over-fiber (UWBoF) which attracts increasing interest in recent years [16,17]. This new technology can be considered as interdisciplinary field combining the best of the optical and wireless words and makes use of the concepts behind optical fiber-based access technologies such as fiber-to-the-home and fiber-to-thebuilding [3]. Impulse radio UWBoF communication exhibits additional features such as $[3,18]$

(i) No RF carrier modulation is required at the transmitter side, the signal is transmitted through the fiber in UWB native format.

(ii) No RF up-conversion is required at the receiver side. The UWB signals can simply photodetected, filtered and radiated to establish a wireless communication.

The transmission performance of IR-UWB signals over fiber link has been investigated both theoretically and experimentally in the literature. The main point under investigation was to photonically generate IR-UWB signals and address its transmission characteristics over single-mode fiber (SMF) or multi-mode fiber. For example, Pan and Yao [19] presented a comprehensive study on the implementation of multiple modulation schemes in an UWBoF system based on a polarization modulation and an electrical reconfigurable asymmetric Mach-Zehnder interferometer, A $625 \mathrm{Mb} / \mathrm{s}$ UWBoF system with $20 \mathrm{~km} \mathrm{SMF}$ and wireless transmission was demonstrated with error-free operation along with power penalties less than $1.8 \mathrm{~dB}$. Pham et al. [20] proposed and demonstrated a simple system supporting flexible gigabit wireline and IR-UWB wireless access for UWBoF system based on multi-subcarrier up conversion. The proposed system was experimentally demonstrated with the performances of $2 \mathrm{~Gb} / \mathrm{s}$ data in both baseband and UWB formats after $46 \mathrm{~km}$ SMF transmission and further $0.5 \mathrm{~m}$ wireless for UWB data. Li et al. [17] proposed and demonstrated a flexible UWBoF system using various modulation schemes. The results reveal that transmission of $1 \mathrm{~Gb} / \mathrm{s}$ UWB signal over $20 \mathrm{~km}$ SMF is possible with power penalty less than $1 \mathrm{~dB}$ introduced by the fiber dispersion. Yu et al. [3] experimentally demonstrated photonic generation of the FCC compliant UWB signals by utilizing the relaxation oscillations of a semiconductor laser. The proposed method used to perform the transmission of $1 \mathrm{~Gb} / \mathrm{s}$ IR-UWB signal over $23 \mathrm{~km}$ SMF.

The aim of this paper is to assess the transmission performance of IR-UWB signals over optical link consisting of SMF, dispersion compensating fiber (DCF), and optical amplifiers. The investigation covers both monocycle and 5th-order Gaussian UWB systems operating under ON-OFF keying (OOK) and Biphase modulation (BPM) formats. The motivation behind this investigation is to address the possibility of transmission the UWB signals over long existing fiber link (> 30 $\mathrm{km}$ ) and to use the results as a guideline to investigate the transmission of UWB signals with existing WDM networks [21, 22].

\section{2- SYSTEM MODEL}

Figure 1 shows a simplified model for the optical IR-UWB transmitter corresponding to both OOK and BPM signaling. The arbitrary wave generator (AWG) produces a train of $n^{\text {th }}$-order derivative Gaussian pulses and consists of a Gaussian pulse generator followed by an $n^{\text {th }}$-order differentiator. The output of the AWG is encoded by the binary data using high speed unipolar/bipolar electronic switch. For seek of simplicity, the repetition rate of the $\mathrm{n}^{\text {th }}$-order derivative Gaussian pulses is set equal to the data rate.

The output of the Gaussian pulse generator can be expressed as

$$
g_{s}(t)=\sum_{-m}^{m} g\left(t-k T_{0}\right)
$$

where $T_{0}$ is the repetition period and $g(t)$ is a single Gaussian pulse 
$g(t)=\exp \left(\frac{-2 t^{2}}{\pi^{2}}\right)$

In eqn. 1b, $\boldsymbol{\tau}$ represents the full-width of the Gaussian pulse corresponding to $\mathrm{e}^{-1}$ point. The full-width at half-maximum

$(\mathrm{FWHM})(\Delta t)_{F W H M}=\sqrt{\ln 2} \tau=0.833 \tau$.

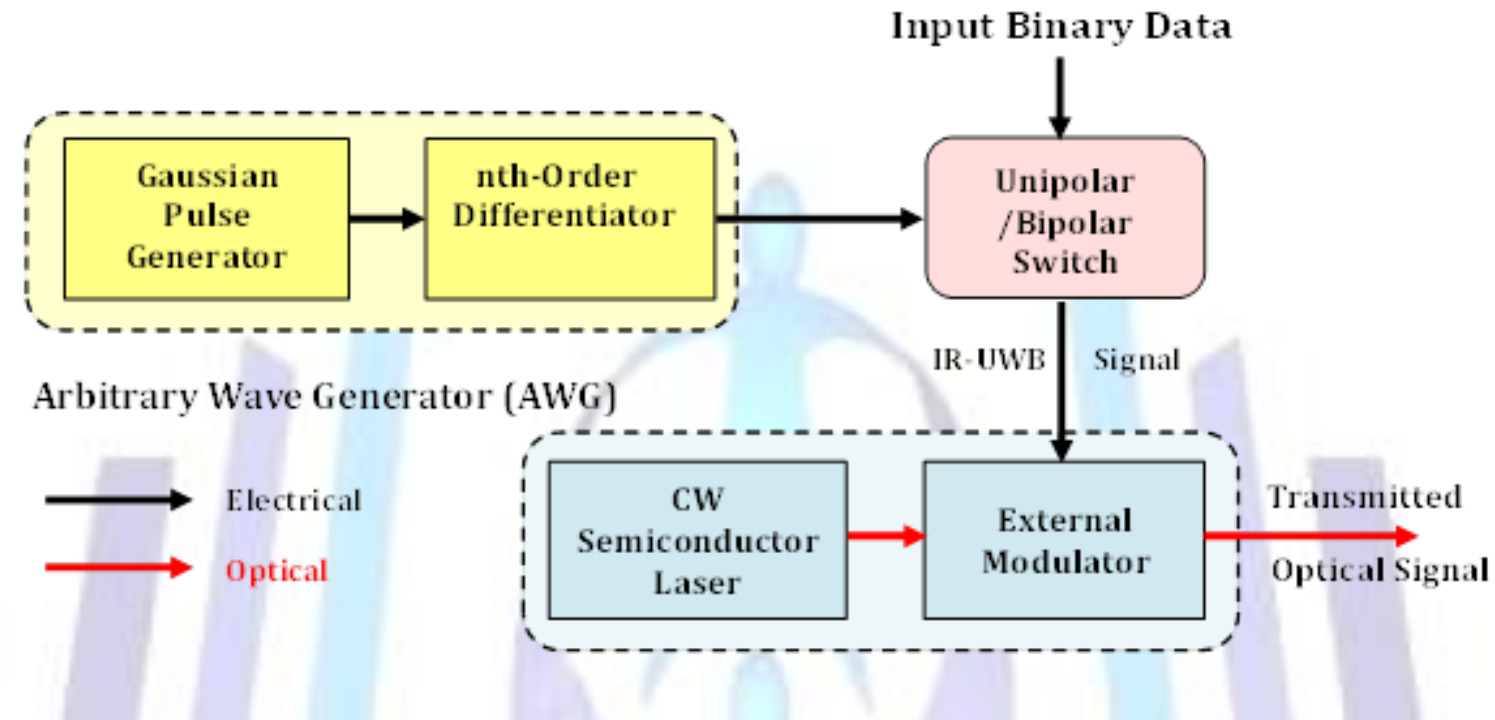

Fig. 1: Block diagram of the optical IR-UWB transmitter.

The output of the AWG, corresponding to train of $n^{\text {th }}$-order derivativeGaussian pulses, is given by

$g_{n s}(t)=\sum_{-m}^{m} g_{n}(t)$

where

$g_{n}(t)=\frac{d^{n}}{d t^{n}} g(t)$

The output of the electronic switch can be expressed

$e_{0}(t)=d(t) g_{n s}(t)$

where $d(t)$ represents the binary data as follow

$d(t)=\left\{\begin{array}{l}1 \\ 0\end{array} \quad\right.$ OOK 
$d(t)=\left\{\begin{array}{rr}1 & \text { BPM } \\ -1\end{array}\right.$

The bipolar switch used to generate the BPM signaling can be implemented using two unipolar switches as shown in Fig. 2.

The RF signal $e_{0}(t)$ is used to modulate the intensity of a continuous wave $(\mathrm{CW})$ semiconductor laser using external modulator. The power of the modulated optical carrier at the modulator output can be written as

$p(t)=P_{o}\left[1+m e_{o}(t)\right]$

where $P_{0}$ is the CW laser power and $m$ is the modulation index.

The optical IR-UWB receiver is essentially an energy detector and can be modeled by a photodiode followed by an electrical signal processing unit as shown in Fig. 3.

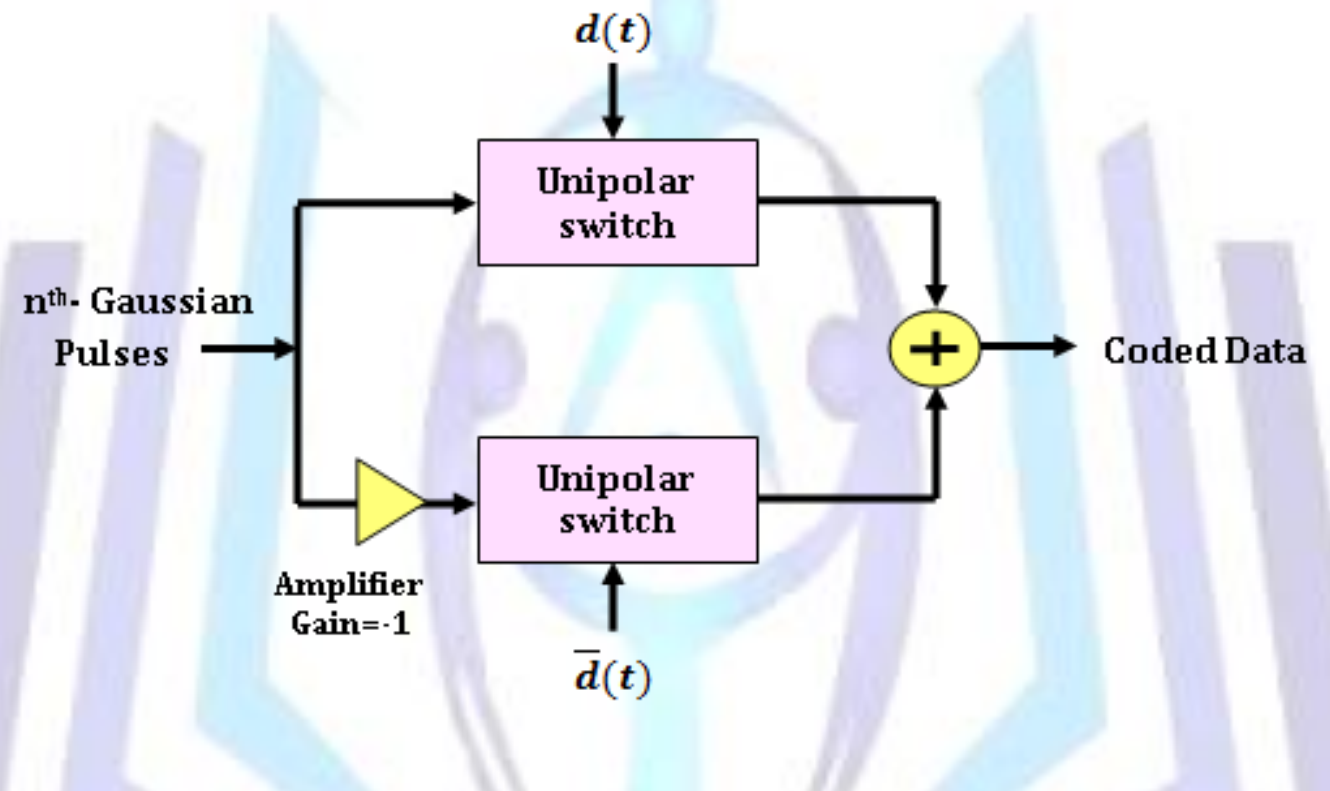

Fig. 2: Simplified block diagram of the bipolar switch. The binary data $\bar{d}(t)$ is obtained from $\mathrm{d}(\mathrm{t})$ through logical NOT operation.

The RF photocurrent $i_{p h}(t)$ generated by the photodiode is passed through a low noise amplifier (LNA) and a bandpass filter (3.1-10.6 GHz) before driving the IR-UWB transmission antenna. The LNA and the bandpass filter are used to fit the PSD of the generated RF signal with FCC mask. The bandpass filter is used with the Gaussian monocycle system since the PSD of the RF signal contains low frequency components which may interfere with other existing wireless systems such as global positioning system (GPS) [21]. 


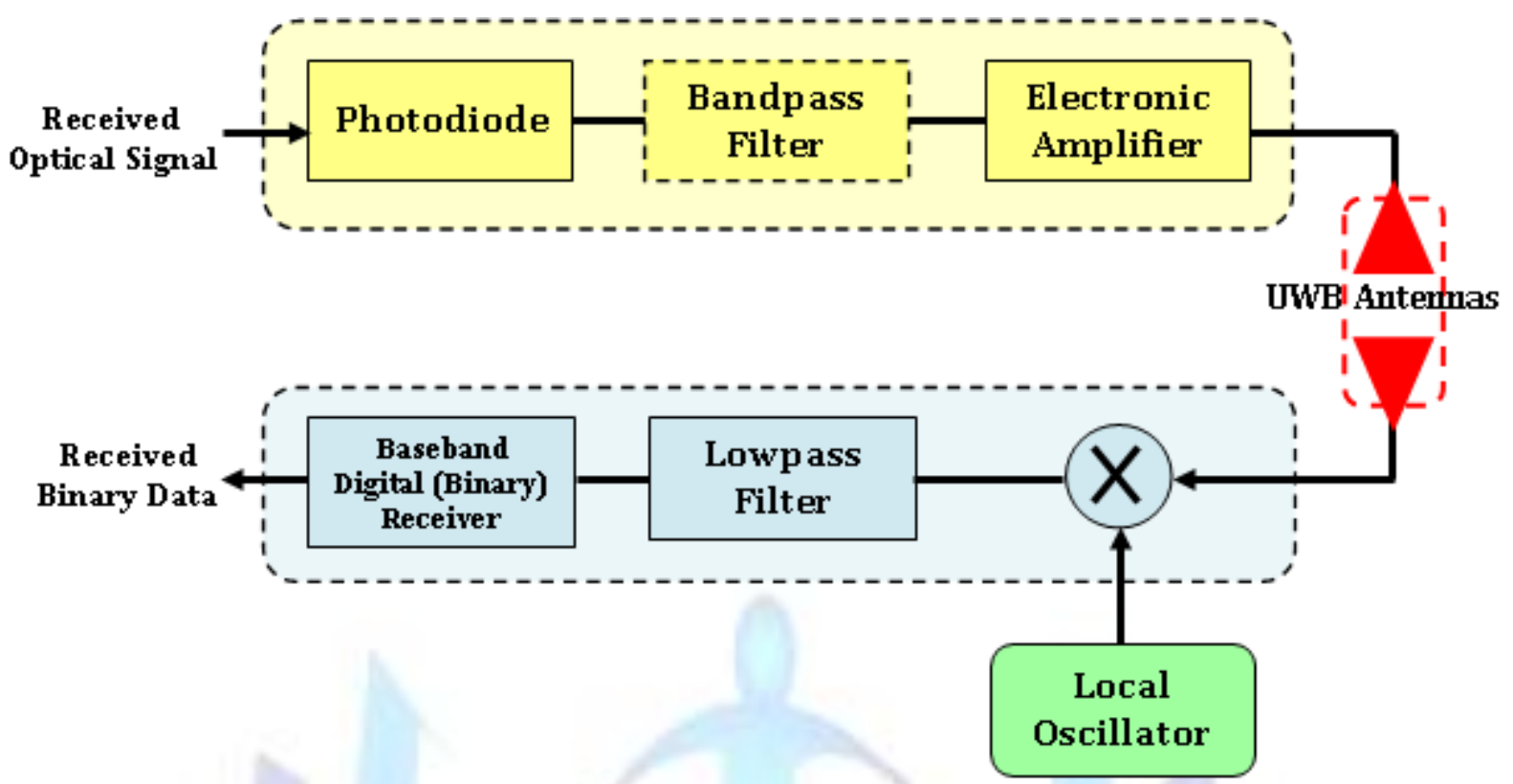

Fig. 3: Block diagram of the IR-UWB receiver.

The radiated $\mathrm{RF}$ signal will be detected by the corresponding IR-UWB receiving antenna. The resultant RF signal is then down converted to the baseband using RF mixing with local oscillator (LO). The LO is assumed to be fully synchronized withone of the harmonics of the Gaussian pulses using phase-locked loop technique. The mixer output is filtered using a low pass filter having a cutoff frequency equals to $(0.75 \times$ bit rate) to reject unwanted frequencies. The filtered signal is then DC-blocked to remove the DC component before applying to a baseband digital (binary) receiver. This device compares the sample value of the bit under observation with a threshold level to decide the logic of the detected bit (i.e., logic 1 or logic 0$)$.

The Gaussian train of pulses described by eqn. 1a can be expanded using Fourier series

$g_{s}(t)=\frac{a_{a}}{2}+\sum_{k=1}^{m} a_{k} \cos \left(k \omega_{0} t+\emptyset_{k}\right)$

where $\omega_{0}=2 \pi f_{0}=2 \pi / T_{0}$ is the fundamental radian frequency and

$a_{k}=\frac{2}{T_{s}} \int_{0}^{T_{s}} g(t) \cos \left(k \omega_{0} t\right) d t$

the $\mathrm{n}^{\text {th }}$-order derivative pulse series (eqn. 2a) can be expanded as

$g_{n s}(t)=\sum_{k=1}^{\mathrm{s}} A_{k} \cos \left(k \omega_{0} t+\Phi_{k}\right)$

where $A_{k}$ is the amplitude of the $k^{\text {th }}$-harmonic of $g_{n s}(t)$ and

$A_{k}=\left(k \omega_{0}\right)^{n} a_{k}$

$\Phi_{k}=\emptyset_{k}+n \pi / 2$

Note that both $g_{s}(t)$ and $g_{n s}(t)$ waveforms have the same repetition period $T_{0}$ and they are periodic functions of time. However, $g_{n s}(t)$ has no DC component since it is generated from $g_{s}(t)$ after applying differentiation process. Note further, $g(t)$ according to eqn. $1 \mathrm{~b}$ is a real even function of time. Therefore, $\varphi_{k}$ and $\phi_{k}=0$ for all values of $k(k \geq 1)$.

The Fourier series coefficients $a_{k}$ are proportional to the amplitudes of the samples obtained by sampling the Fourier transform of $g(t)$ at $k T_{0}$ instances. The Fourier transform of the $g(t)$ is given by 
$\mathrm{G}(\omega)=\sqrt{\pi / 2} \tau \exp \left(\frac{-\omega^{2} \mathrm{~T}^{2}}{g}\right)$

(9)

Note that $G(0)=\sqrt{\pi / 2} \tau$ and the $\mathrm{e}^{-1}$ bandwidth is given by $\Delta \omega=2 / \tau$. The FWHM bandwidth is related to $\Delta \omega$ by

$(\Delta \omega)_{F W H M}=\sqrt{\ln 2} \Delta \omega=0.833 \Delta \omega$. Therefore

$(\Delta \omega)_{F W H M}=\frac{2 \ln 2}{(\Delta)_{\text {FWHM }}}$

It is clear from eqn. 9 that $a_{k}$ is proportional to $\exp \left(\frac{-\left(\tau k \omega_{s}\right)^{2}}{8}\right)$ and hence it is positive and a decreasing function of $k$. According to eqn. 8

$A_{k} \propto\left(k \omega_{0}\right)^{n} \exp \left(\frac{-\left(\pi k \omega_{0}\right)^{2}}{8}\right)$

where the symbol $a$ denotes proportionality.

Note that $A_{k}$ is the product of two terms, one is an increasing function of $k$ while the other is a decreasing function of $k$. Therefore, there is a certain value of $k$ which maximizes $A_{k}$. This can be obtained by considering $k$ as a continuous variable and setting $d A_{k} / d k$ to zero

$\left(k \omega_{0}\right)^{n}\left[-\left(\frac{\left(\tau k \omega_{0}\right)^{2}}{4}\right) \cdot \exp \left(\frac{-\left(\tau k \omega_{0}\right)^{2}}{8}\right)\right]+\left[\exp \left(\frac{-\left(\tau k \omega_{0}\right)^{2}}{8}\right) \cdot\left(n \omega_{0}^{n} k^{n-1}\right)\right]=0$

This leads to

$\frac{\left(\pi k \omega_{s}\right)^{2}}{4}=n$

Therefore

$k=\frac{2 \sqrt{n}}{\pi \omega_{s}}=\frac{\sqrt{n}}{\pi t f_{s}}=\frac{\sqrt{n}}{\pi}{ }_{\frac{T}{s}}$

Equation 12 reveals that the order of the highest-level harmonics increases with $\sqrt{\mathrm{n}}$. For monocycle and $5^{\text {th }}$-order derivative Gaussian pulses, the values of $k$ corresponding to the highest-level harmonics are related by $k_{5} / k_{1}=\sqrt{5}$.

The analysis can be carried further to describe the generated photocurrent. For seek of simplicity, the effect of fiber (losses, dispersion and nonlinear fiber optics) and system noise (amplifier spontaneous emission noise and receiver thermal noise) are neglected. Under this optimistic situation, the photocurrent is given by

$i_{p h}(t)=R p(t)$

where $R$ is the photodiode responsitivity. Using eqns. 3a and 4 into eqn. 13a leads to

$i_{p}(t)=R P_{o}\left[1+m d(t) g_{n s}(t)\right]$

After blocking the DC component

$$
i_{p}(t)=R m d(t) \sum_{k=1}^{m} A_{k} \cos \left(k \omega_{0} t+\Phi_{k}\right)
$$

Equation 14 characterizes that the photocurrent is a series of double-side band suppressed carrier (DSB/SC) signals generated by modulating the harmonics of the $n^{\text {th }}$-order derivative Gaussian pulse train by the data $d(t)$. The data can be recovered from any DSB signal using a coherent (synchronous) demodulation based on mixing the received signal with LO which is synchronized with one of the harmonics. To increase SNR at the demodulation output, synchronization should be done with one of the highest-level harmonics.

\section{3- IMPULSE RADIO ULTRA WIDE BAND (IR-UWB) OVER FIBER}

Recently there is increasing interest in transmitting IR-UWB signals over long distances of existing SMF transmission links. Unfortunately, the performance of such transmission, designed to operate at $1550 \mathrm{~nm}$ wavelength, is degraded mainly by the fiber group-velocity dispersion (GVD) due to the wide spectrum of the transmitted signals. To solve this problem, it is assumed here that DCF is used at the end of the SMF section to compensate its dispersion as shown in Fig. 4. Two optical amplifiers of gains $G_{1}$ and $G_{2}$ can be inserted after the SMF and DCF, respectively, to compensate the losses. The length of the DCF can be a part of the transmission link length or just inserted as a loop at the dropping node. This leaves the SMF length determining the transmission link length.

Let the SMF (DCF) is characterized by $L_{S M F}\left(L_{D C F}\right)$ length, $D_{S M F}\left(D_{D C F}\right)$ group-velocity dispersion, and $\alpha_{S M F}\left(\alpha_{D C F}\right)$ loss measured in $\mathrm{dB} / \mathrm{km}$. Therefore the gains of the two amplifiers (measured in $\mathrm{dB}$ ) are given by $G_{1}=\alpha_{S M F} L_{S M F}$ and $G_{2}=\alpha_{D C F}$ $L_{D C F}$. Further, to achieve full dispersion compensation 
$D_{S M F} L_{S M F}+D_{D C F} L_{D C F}=0$

The required length of the DCF is

$L_{D C F}=-\frac{D_{\text {SMF }}}{D_{\text {DCF }}} L_{\text {SMF }}$

The DCF is designed to have negative GVD at $1550 \mathrm{~nm}$ to compensate the positive dispersion of the SMF at this wavelength. The length of the transmission link $L_{T}=L_{S M F}+L_{D C F}=\left(1-D_{S M F} / D_{D C F}\right) L_{S M F}$ when DCF is used as a part of the transmission link; otherwise $L_{T}=L_{S M F}$.

Two modifications can be introduced to the system configuration shown in Fig. 1

(i) The two optical amplifiers can be replaced by a single amplifier, inserted at the end of the DCF, having gain of $G_{T}$ $=G_{1}+G_{2}$ in (decibels).

(ii) An optical bandpass filter can be inserted at the receiver input to suppress partially the amplified spontaneous emission (ASE) generated by the optical amplifiers, that incident on the photodiode. This leads to an increase in the receiver performance.

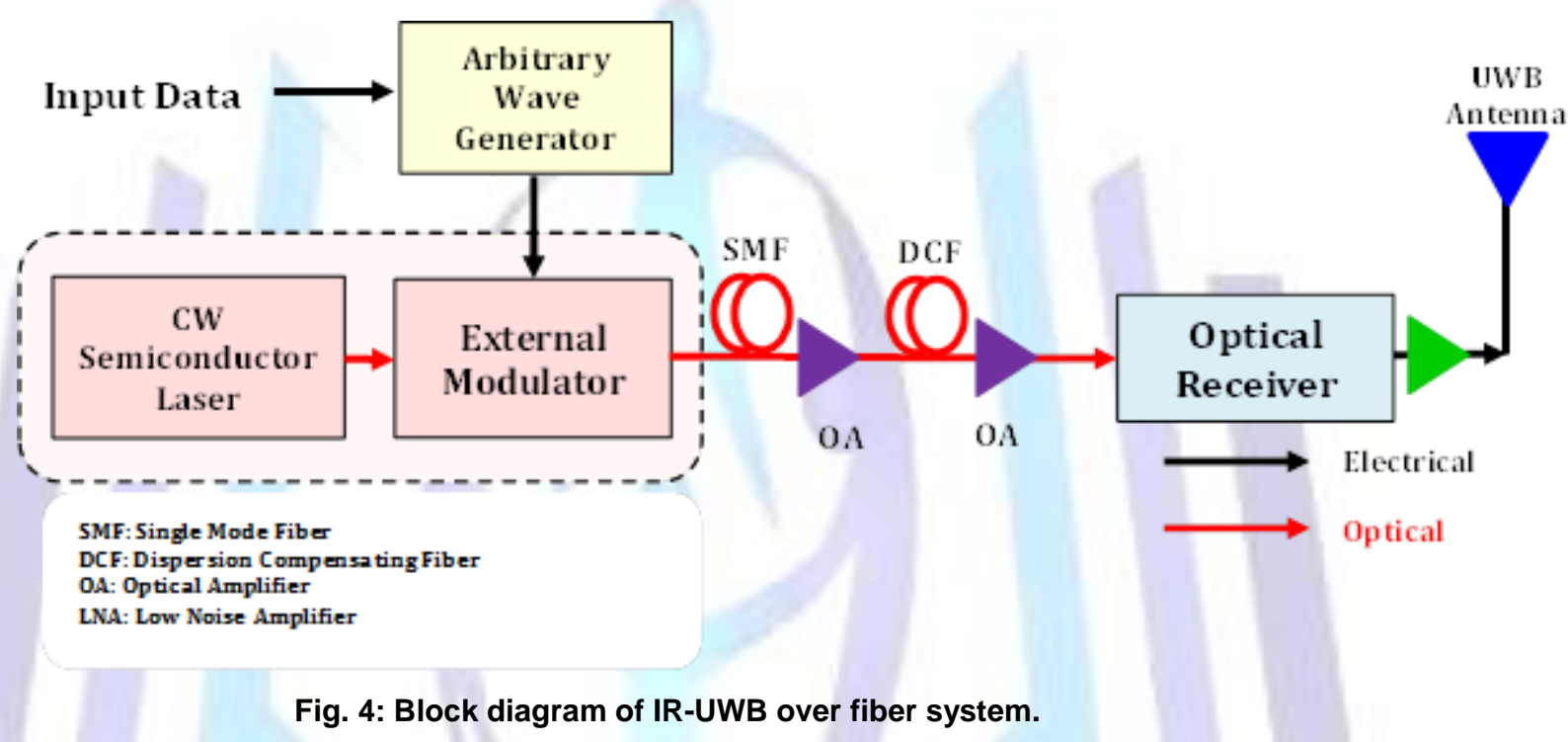

The parameters values of the SMF and DCF used in the simulation are listed in Table 1 for $1550 \mathrm{~nm}$ operation. Unless otherwise stated, the data rate is $625 \mathrm{Mb} / \mathrm{s}$ and the waveform generator produces $\mathrm{n}^{\text {th }}$-order derivative Gaussian pulses at $625 \mathrm{MHz}$ repetition rate. The FWHM of the basic Gaussian pulses $\tau$ is set to $85 \mathrm{ps}$. The laser diode emits $0 \mathrm{dBm}$ power under $\mathrm{CW}$ operation at $1550 \mathrm{~nm}$. According to Table $1, \mathrm{D}_{\mathrm{SMF}}=17 \mathrm{ps} /(\mathrm{ns} . \mathrm{nm})$ and $\mathrm{D}_{\mathrm{DCF}}=-85 \mathrm{ps} /(\mathrm{ns} . \mathrm{nm})$ at $1550 \mathrm{~nm}$. Therefore, $L_{T}=1.2 L_{S M F}$ when the DCF is considered as a part of the transmission link.

Table 1: Parameter values for a standard-single mode fiber (SMF) and dispersion compensating fiber (DCF) at $\lambda=1550 \mathrm{~nm}$.

\begin{tabular}{c|c|c}
\hline \hline \multicolumn{1}{c|}{ Parameter } & \multicolumn{2}{|c}{ Value } \\
\cline { 2 - 3 } & SMF & DCF \\
\hline \hline Attenuation, $\alpha$ & $0.2 \mathrm{~dB} / \mathrm{km}$ & $0.5 \mathrm{~dB} / \mathrm{km}$ \\
\hline Group velocity dispersion, D & $17 \mathrm{ps} /(\mathrm{ns} . \mathrm{nm})$ & $-85 \mathrm{ps} /(\mathrm{ns} . \mathrm{nm})$ \\
\hline Dispersion slop & $0.075 \mathrm{ps} / \mathrm{nm} 2 / \mathrm{km}$ & $-0.3 \mathrm{ps} / \mathrm{nm} 2 / \mathrm{k}$ \\
\hline Differential group delay & $0.2 \mathrm{ps} / \mathrm{km}$ & $0.2 \mathrm{ps} / \mathrm{km}$ \\
\hline Effective area, Aeff & $80 \mu \mathrm{m}^{2}$ & $22 \mu \mathrm{m}^{2}$ \\
\hline Nonlinear refractive index, $\mathrm{n} 2$ & $26 \times 10^{-21} \mathrm{~m}^{2} / \mathrm{W}$ & $26 \times 10^{-21} \mathrm{~m}^{2} / \mathrm{W}$ \\
\hline \hline
\end{tabular}




\section{3-1 Gaussian Monocycle Pulses}

This subsection illustrates the transmission performance of the IR-UWB signals over SMF supported by DCF for perfect GVD compensation. The receiver uses RF mixing with $3.75 \mathrm{GHz}$ local oscillator for down conversion. Further, a bandpass filter $(2.5-10.6 \mathrm{GHz})$ is used in the simulation and inserted before the transmitter antenna to fix the spectrum of the transmitted IR-UWB signals within FCC mask. Figure 5 shows the variation of BER with transmission length for OOK and BPM formats. The transmission length is represented by two ways in this figure, one corresponds to the SMF length and the other to the total length $L_{T}=L_{S M F}+L_{D C F}$. To achieve a BER of $10^{-9}$, the SMF length should be less than $77.5 \mathrm{~km}$ and $107.25 \mathrm{~km}$ for OOK and BPM, respectively. These values correspond to total fiber lengths of $93 \mathrm{~km}$ and $128.7 \mathrm{~km}$, respectively.

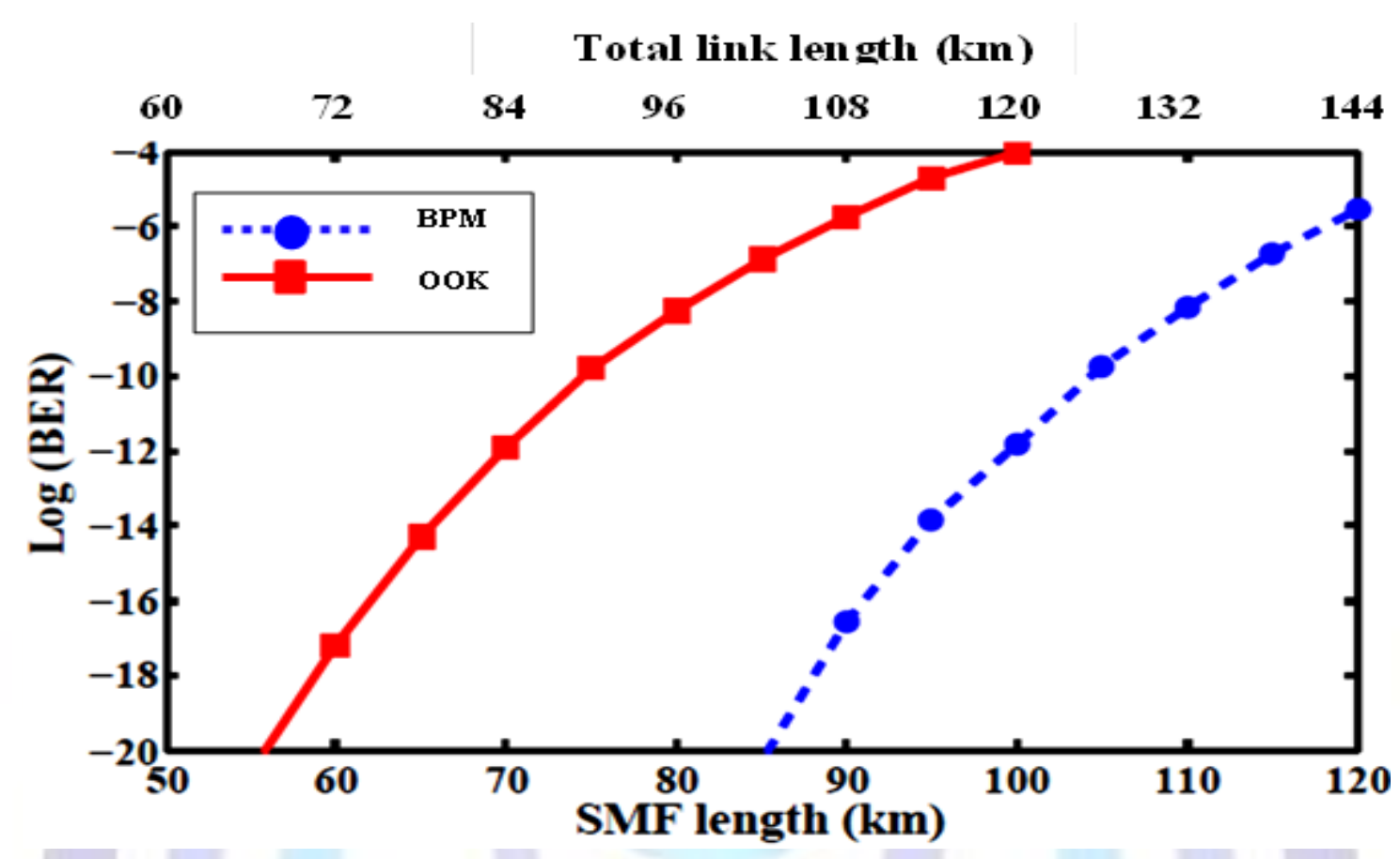

Fig. 5: BER as a function of fiber length for monocycle OOK and BPM modulation formats.

Figures $6 a$ and $b$ show the received eye diagrams after $77.5 \mathrm{~km}$ transmission over a SMF operating without and with DCF, respectively. This SMF length corresponds to a received BER of $10^{-9}$ when DCF is employed. It is clear that the presence of DCF will improve the eye opening and hence improve the BER characteristics. The corresponding power spectrum of the transmitted RF signal is shown in Fig. $6 c$ which contains both discrete and continuous spectra.

The simulations are repeated for BPM and the results are depicted in Fig. 7 using $107.25 \mathrm{~km}$ of SMF. This corresponds to a $B E R=10^{-9}$ when DCF is inserted. Note that the eye diagram is completely closed in the absence of DCF leading to a $\mathrm{BER}=1$. Note further, that the spectrum of the RF signal lies within the required FCC mask. The improvement gained by using BPM over OOK is expected since the continuous part of its spectrum contains high-level frequency contents. Recall that the average optical power $P_{a v}$ is equal to half the CW laser power $P_{c w}$ in OOK system. In contrast, $P_{a v}=P_{c w}$ in BPM system. 


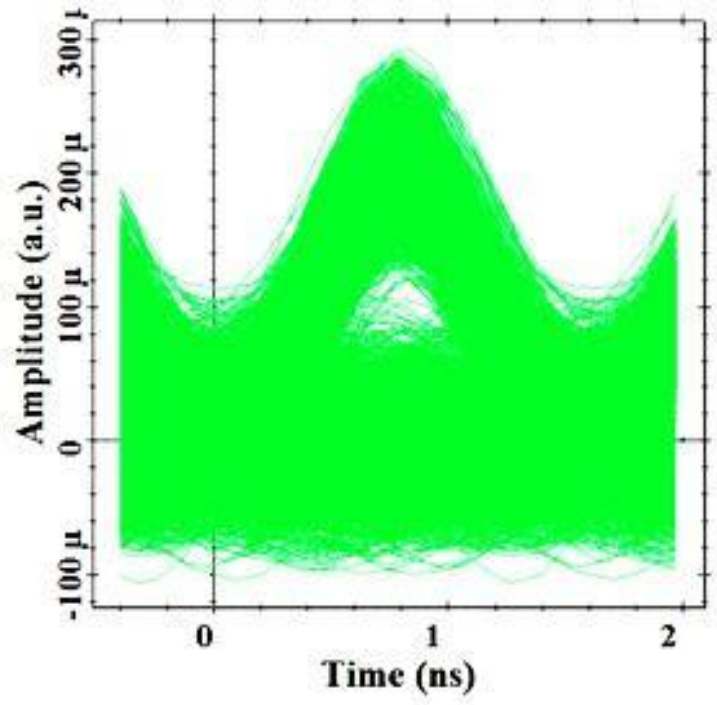

(a)

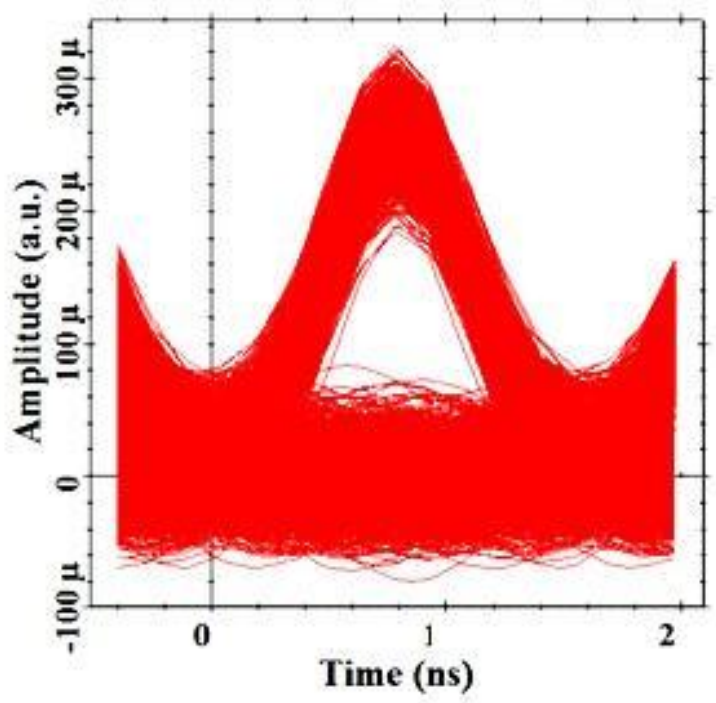

(b)

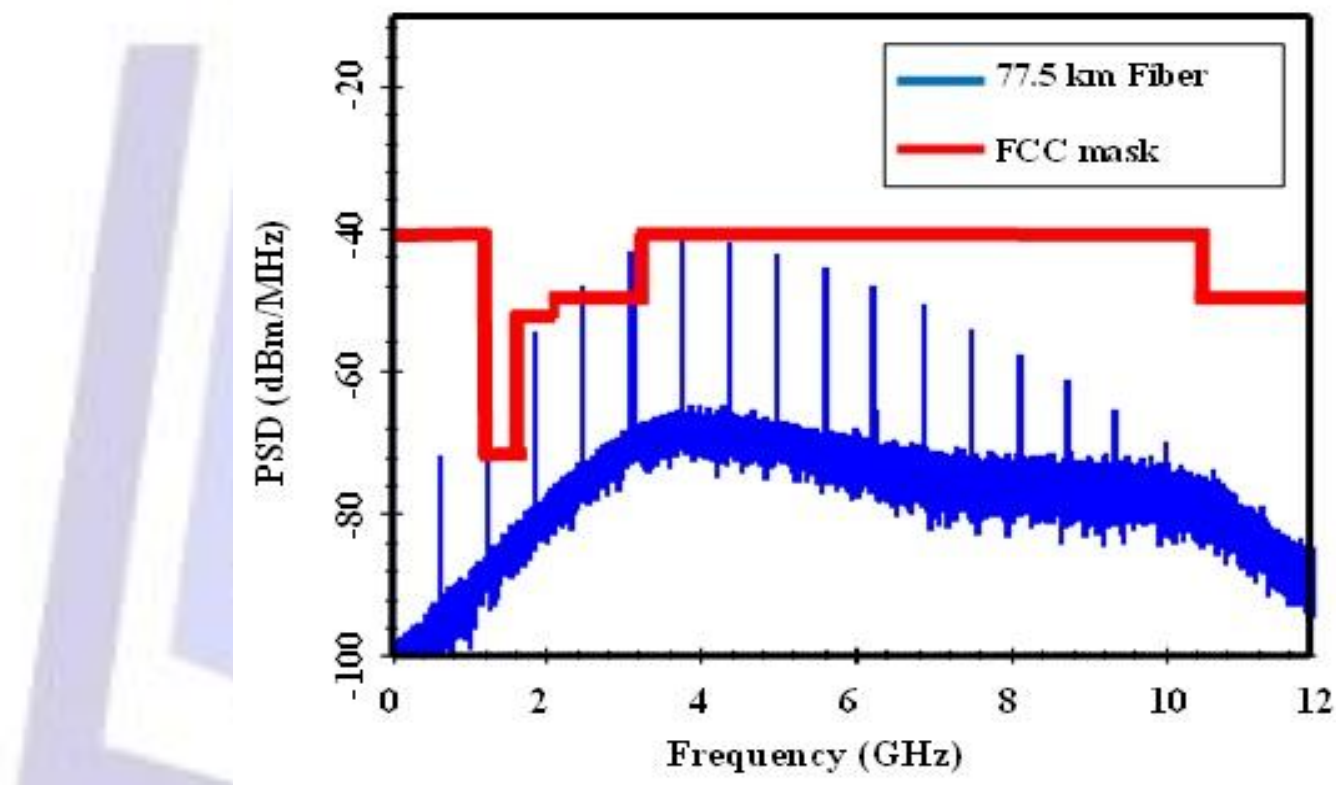

(c)

Fig. 6: Characteristics of the received signal after transmission over $77.5 \mathrm{~km} \mathrm{SMF}$ fiber for $625 \mathrm{Mb} / \mathrm{s}$ OOK monocycle system. (a) Eye diagram when DCF is not used. (b) Eye diagram when DCF is used. (c) Power spectrum density of the transmitted RF signal when DCF is used. 


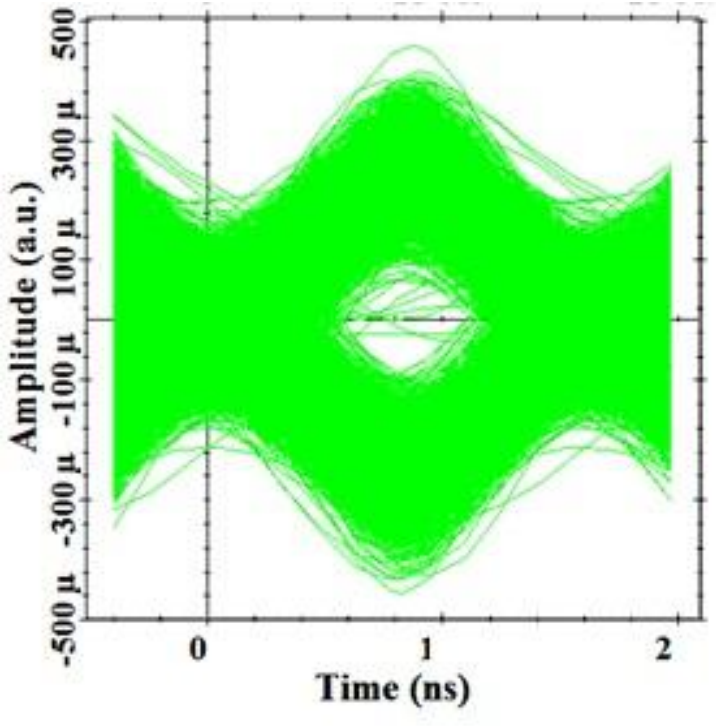

(a)

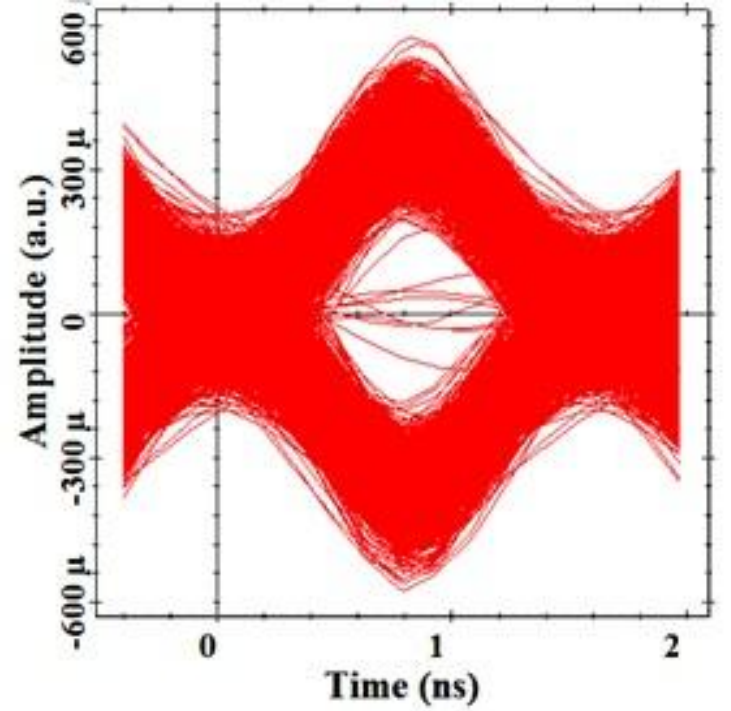

(b)

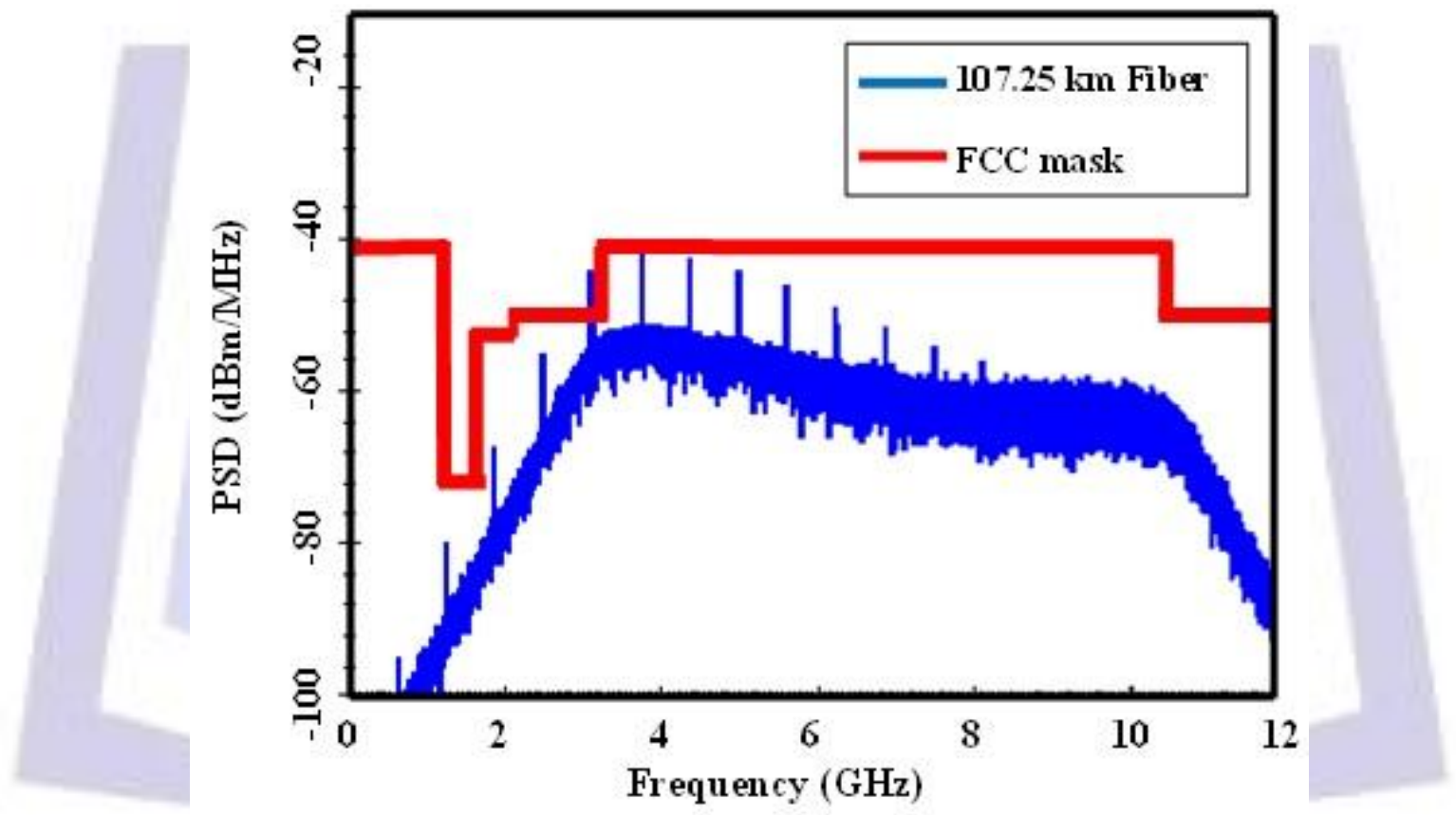

(c)

Fig.7: Characteristics of the received signal after transmission over $107.25 \mathrm{~km}$ SMF fiber for $625 \mathrm{Mb} / \mathrm{s}$ BPM monocycle system. (a) Eye diagram when DCF is not used. (b) Eye diagram when DCF is used. (c) Power spectrum density of the transmitted RF signal when DCF is used.

The effect of using optical filter in front of the receiver is also investigated and the results are depicted in Fig. 8. In this figure, the variation of BER with filter bandwidth is shown for OOK and BPM formats. In each case, the SMF length is chosen to give $B E R=10^{-9}$ in the presence of DCF, i.e., $L_{S M F}=77.5 \mathrm{~km}$ and $107.25 \mathrm{~km}$ for OOK and BPM, respectively. Not that using a $16 \mathrm{GHz}$ bandwidth will improve the BER from $10^{-9}$ to $6.4 \times 10^{-12}$ in the case of OOK signaling. These values are to be compared with $10^{-9}$ to $5.1 \times 10^{-12}$ in the case of BPM signaling. 


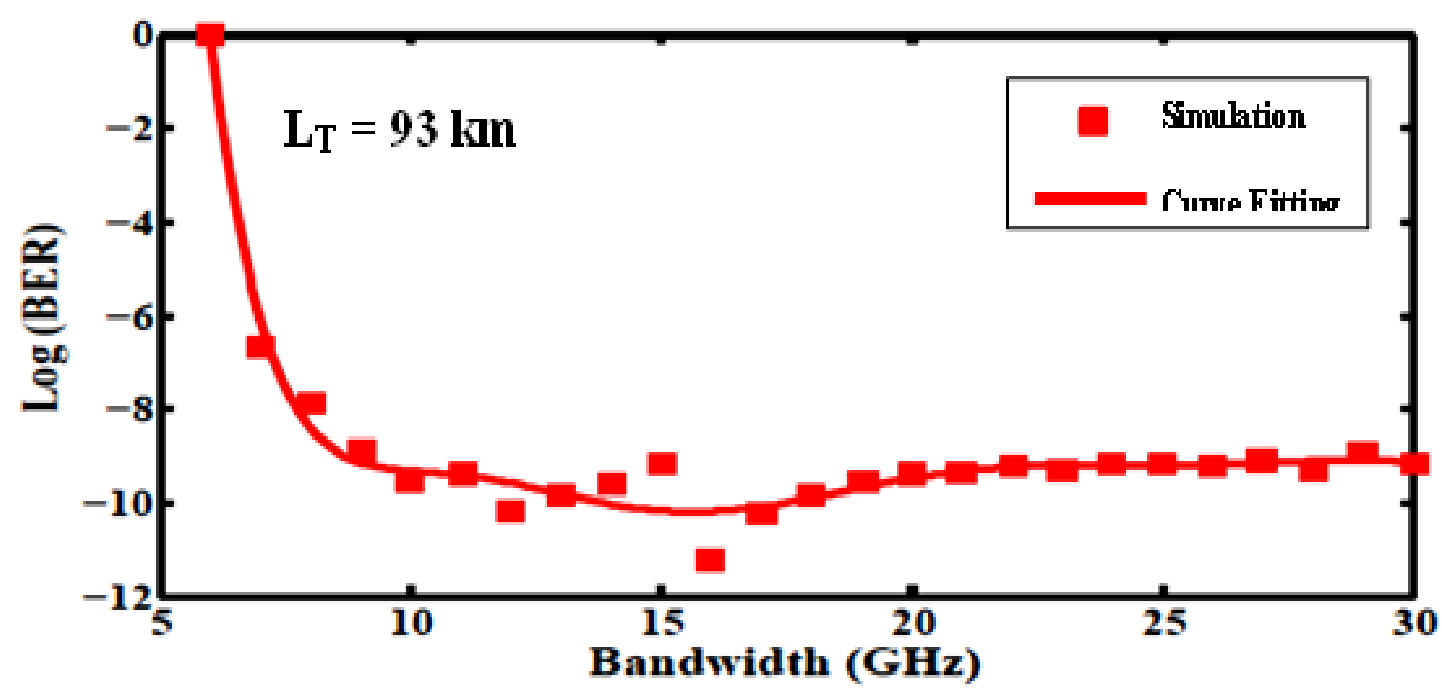

(a)

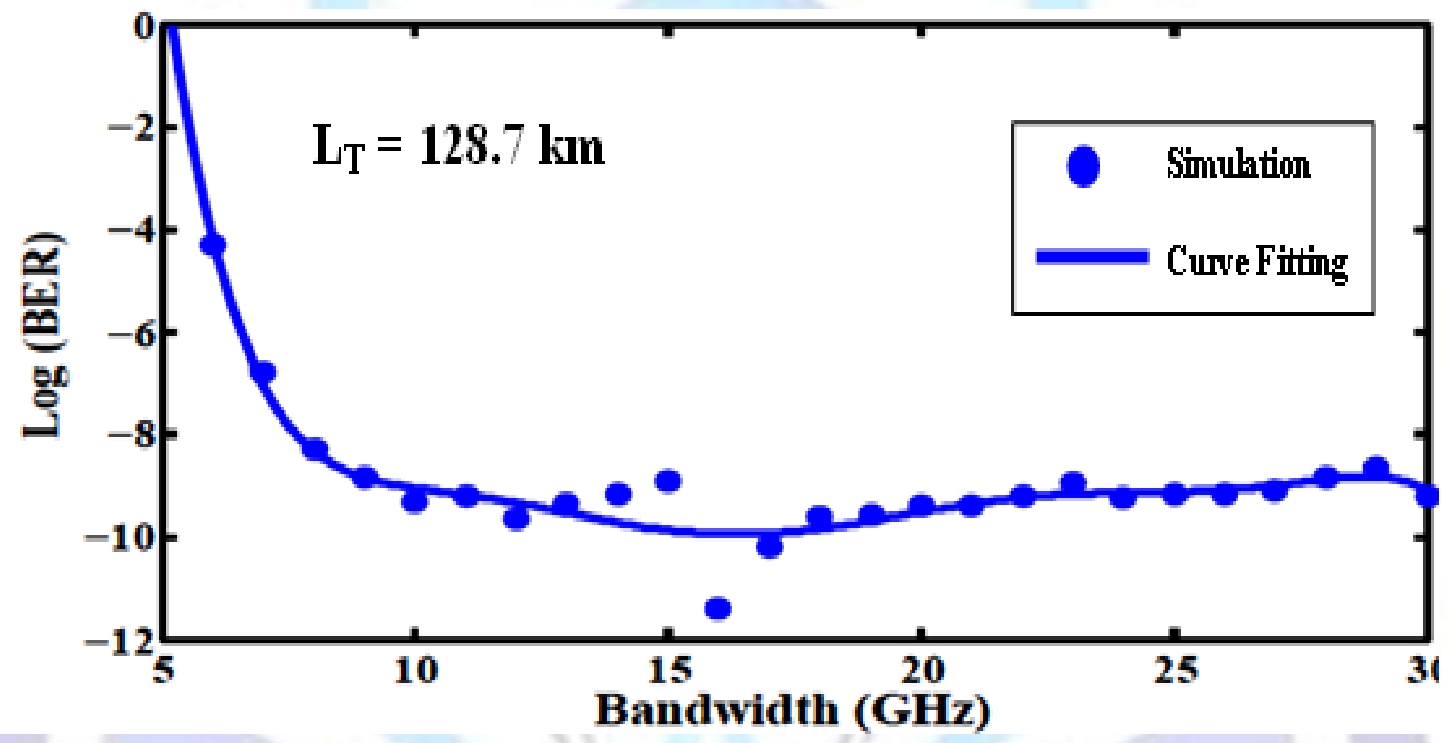

(b)

Fig. 8: BER as a function of optical filter bandwidth for (a) Monocycle OOK (b) Monocycle BPM.

\section{3-2 Fifth-Order Derivative Gaussian Pulses}

This subsection addresses the transmission performance of IR-UWB signals over optical fiber link using $5^{\text {th }}$-order derivative Gaussian pulses. The simulations carried out in the previous section are repeated here for $625 \mathrm{Mb} / \mathrm{s}$ data rate using $8.125 \mathrm{GHz}$ local mixing frequency and the results are reported in Figs. 9-12. The main conclusions drawn from these figures can be compared with the results related to monocycle-based system as listed in Table 2 . This table shows the maximum allowable transmission distance for BERs equal to $10^{-7}$ and $10^{-9}$. 
Table 2: Transmission distances at two given BERs for monocycle and $5^{\text {th }}$-order derivative IR-UWB operating with OOK and BPM modulation formats.

\begin{tabular}{|c|c|c|c|c|}
\hline BER & Pulse type & $\begin{array}{c}\text { Modulation } \\
\text { formats }\end{array}$ & $\begin{array}{l}\text { SMF length } \\
(\mathbf{k m})\end{array}$ & $\begin{array}{c}\text { Total link length } \\
(\mathbf{k m})\end{array}$ \\
\hline \multirow{4}{*}{$10^{-7}$} & \multirow{2}{*}{ Monocycle } & OOK & 85 & 102 \\
\hline & & BPM & 115 & 138 \\
\hline & \multirow{2}{*}{$\begin{array}{c}5^{\text {th }} \text {-order Derivative } \\
\text { Gaussian }\end{array}$} & OOK & 65 & 78 \\
\hline & & BPM & 97 & 116.5 \\
\hline \multirow{4}{*}{$10^{-9}$} & \multirow{2}{*}{ Monocycle } & OOK & 77.5 & 93 \\
\hline & & BPM & 107.25 & 128.7 \\
\hline & \multirow{2}{*}{$\begin{array}{c}5^{\text {th }} \text {-order Derivative } \\
\text { Gaussian }\end{array}$} & OOK & 57 & 68.5 \\
\hline & & BPM & 90 & 108 \\
\hline
\end{tabular}

\section{Total link length (km)}

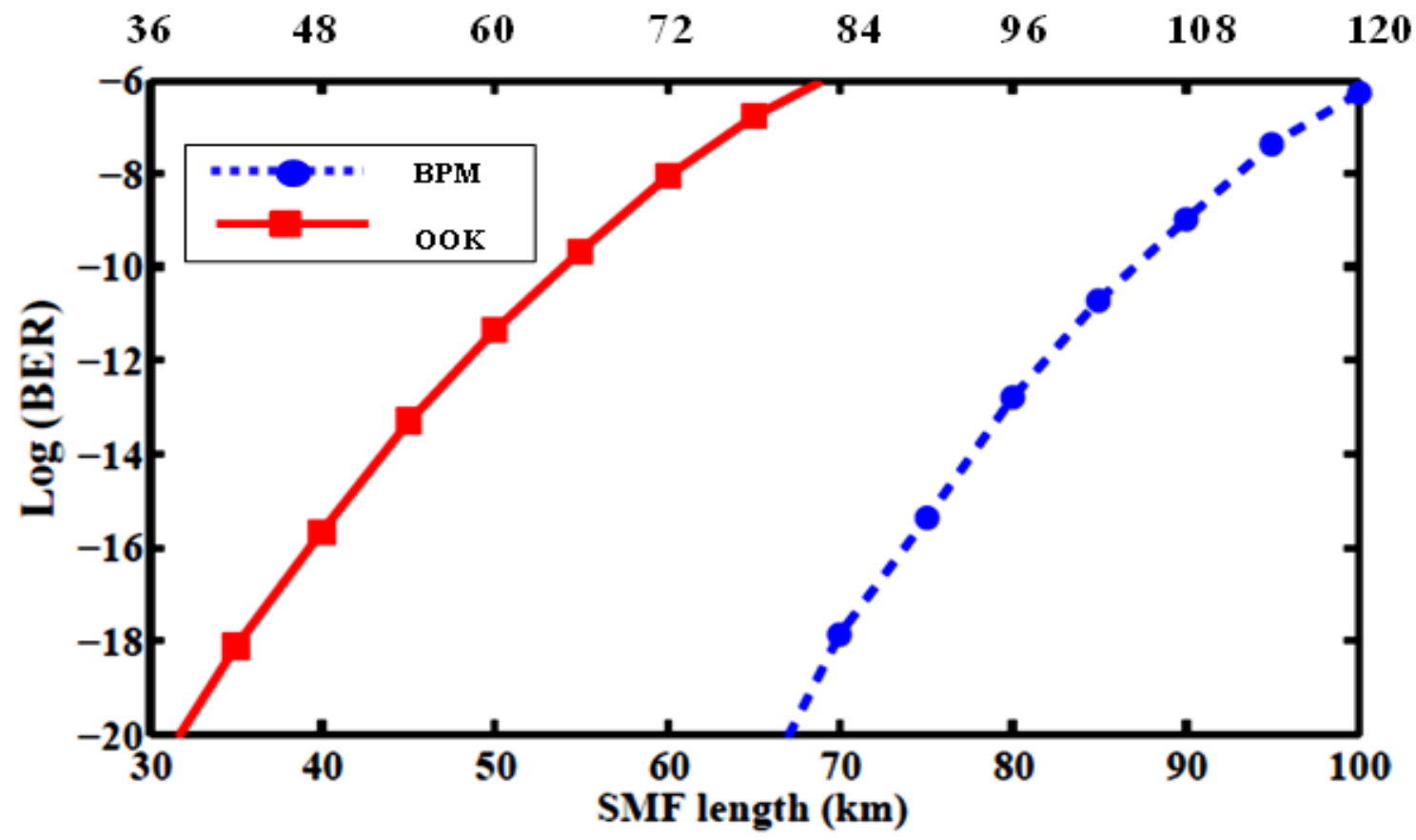

Fig. 9: BER as a function of fiber length for $5^{\text {th }}$-order derivative Gaussian OOK and BPM modulation formats. 


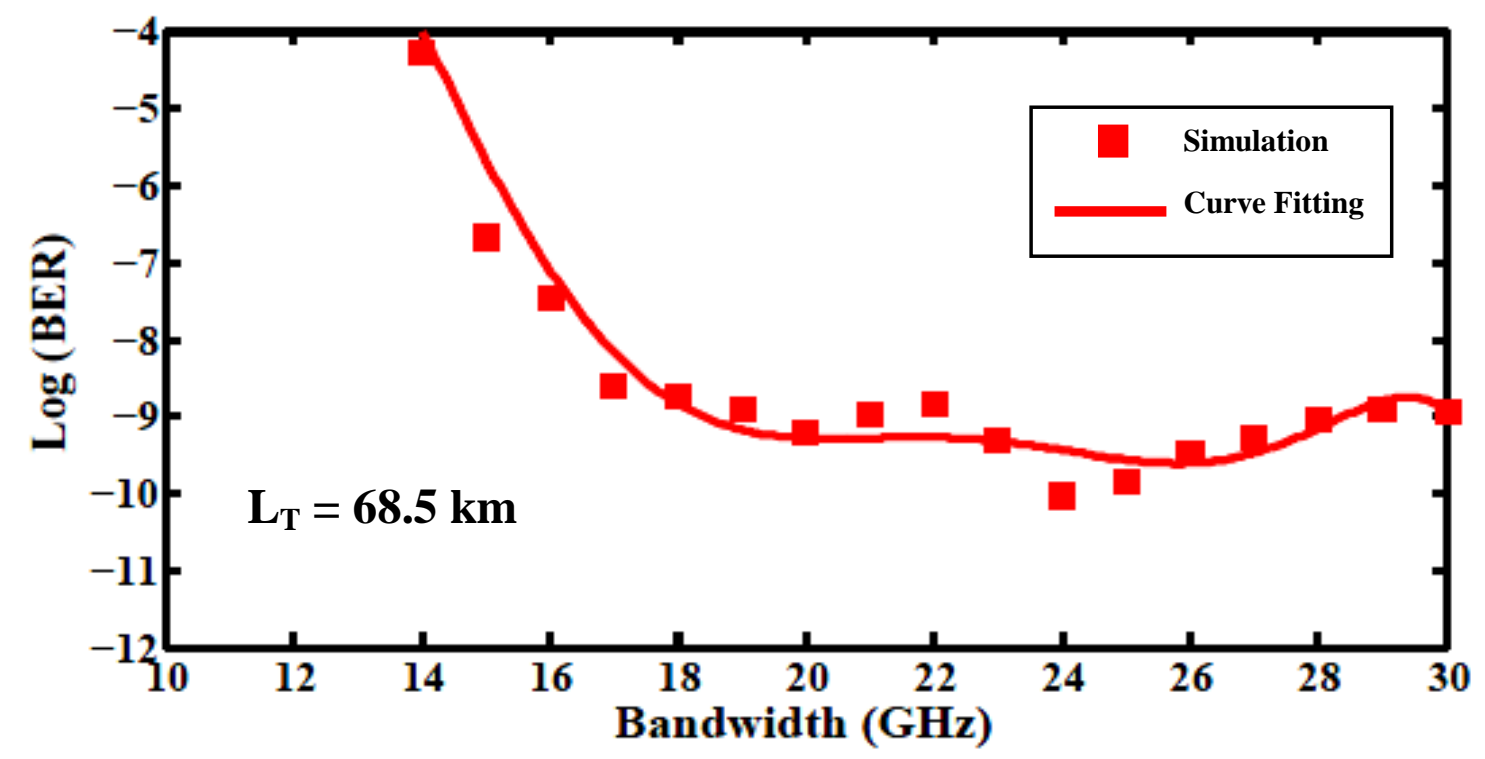

(a)

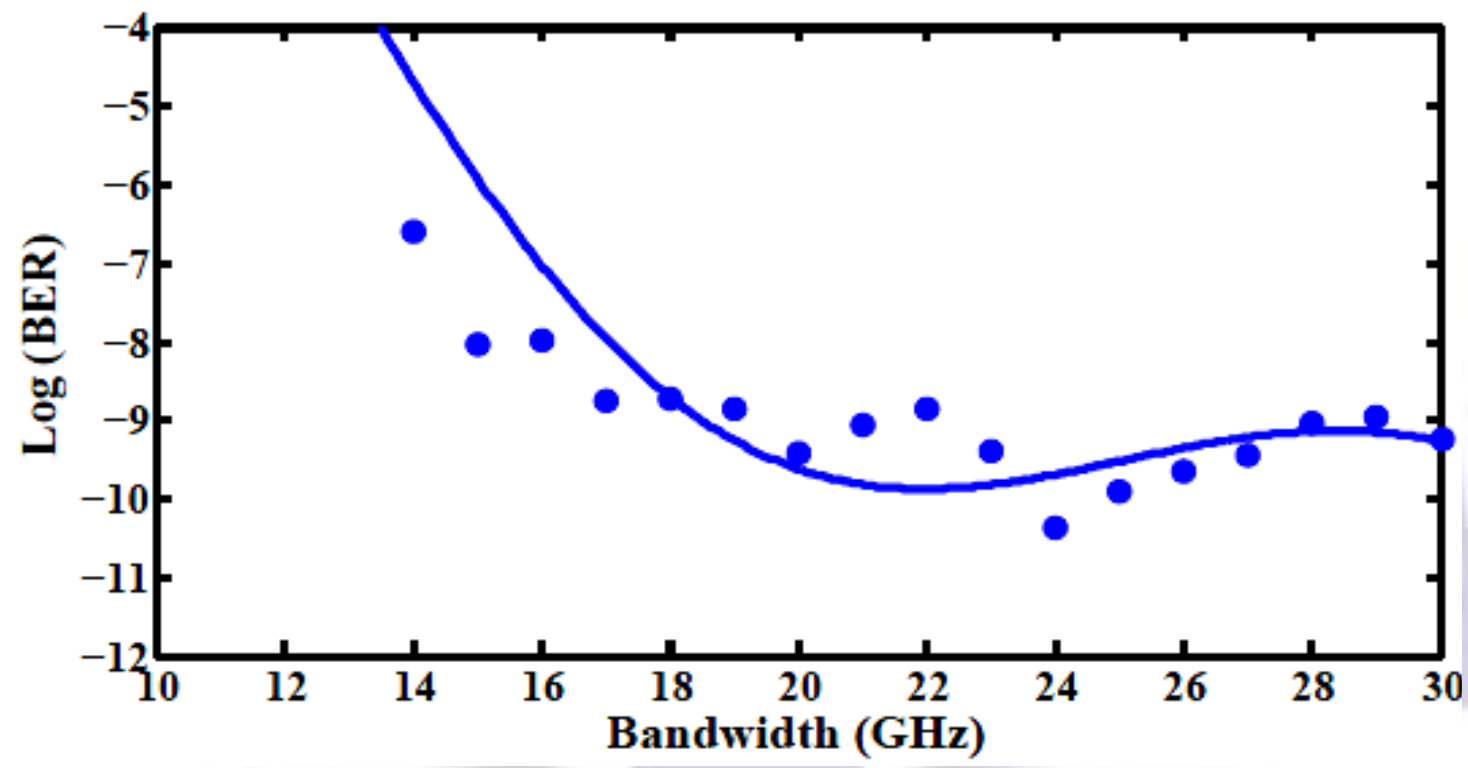

(b)

Fig. 10: BER as a function of optical filter bandwidth for (a) $5^{\text {th }}$-order derivative Gaussian $00 \mathrm{~K}$ (b) $5^{\text {th }}$-order derivative Gaussian BPM. 


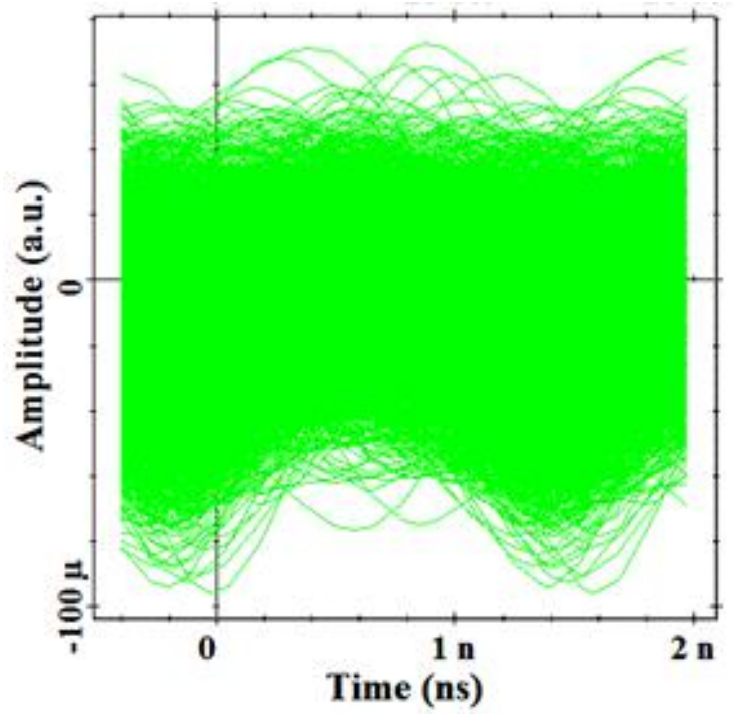

(a)

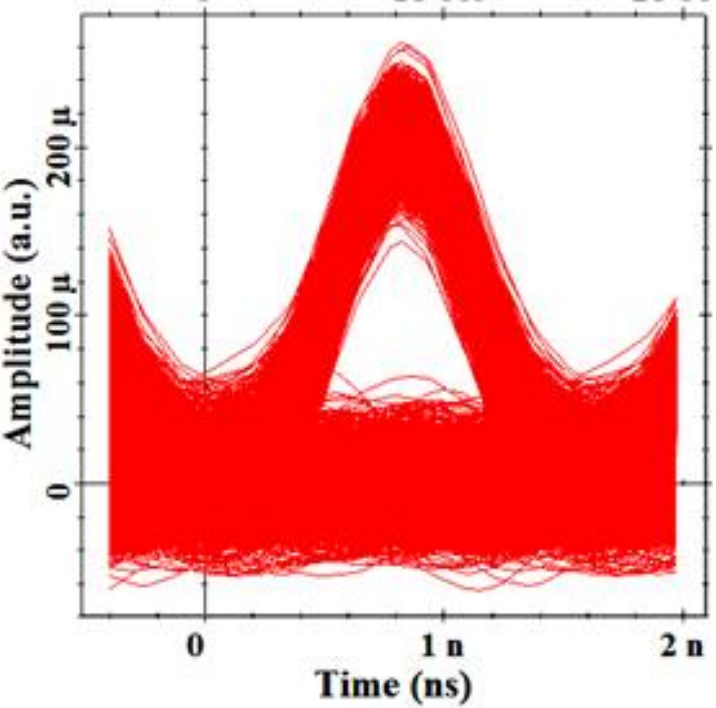

(b)

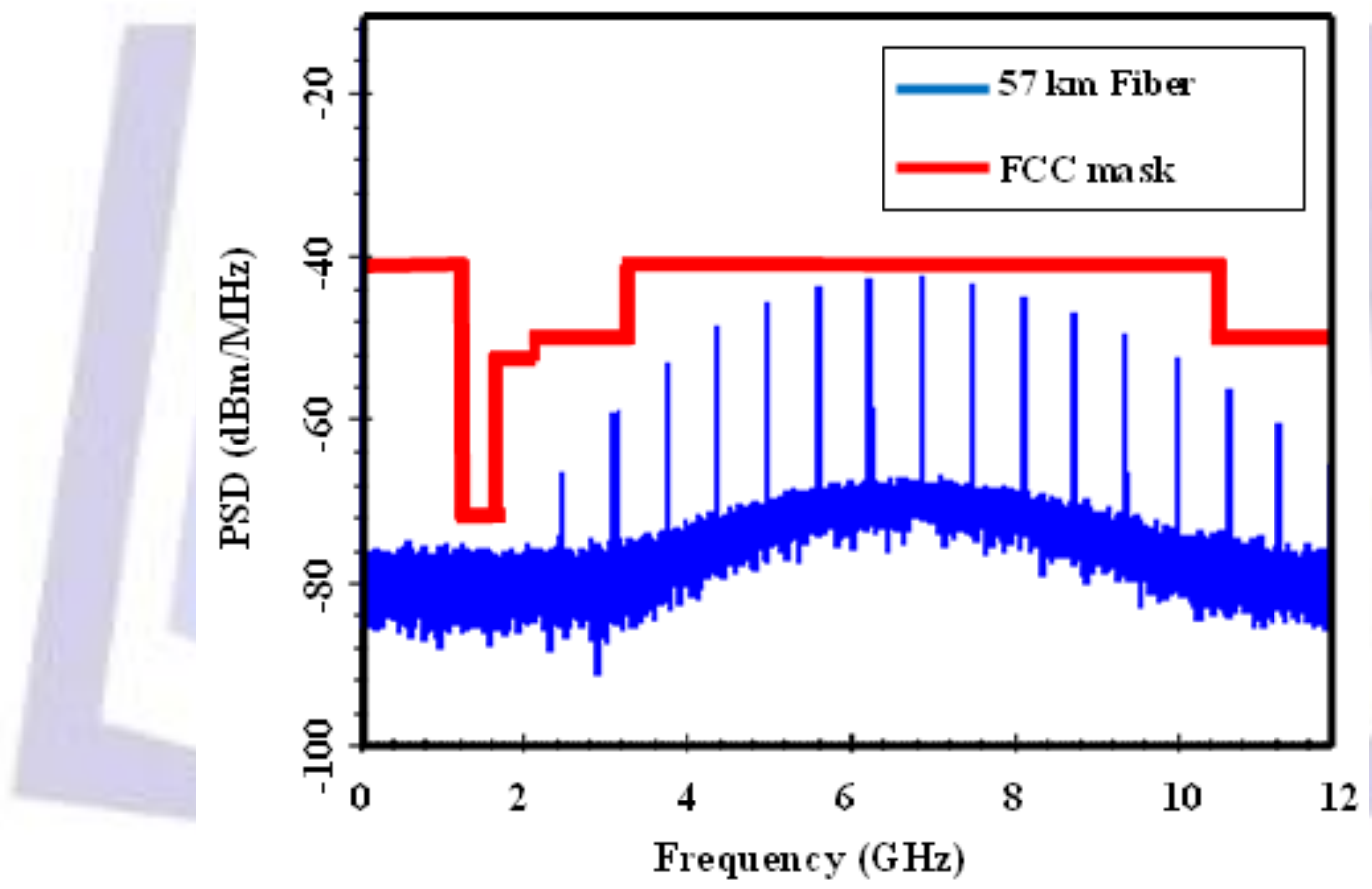

(c)

Fig. 11: Characteristics of the received signal after transmission over $55 \mathrm{~km} \mathrm{SMF}$ fiber for $625 \mathrm{Mb} / \mathrm{s} 5^{\text {th }}$-order derivative Gaussian OOK system. (a) Eye diagram when DCF is not used. (b) Eye diagram when DCF is used. (c) Power spectrum density of the transmitted RF signal when DCF is used 


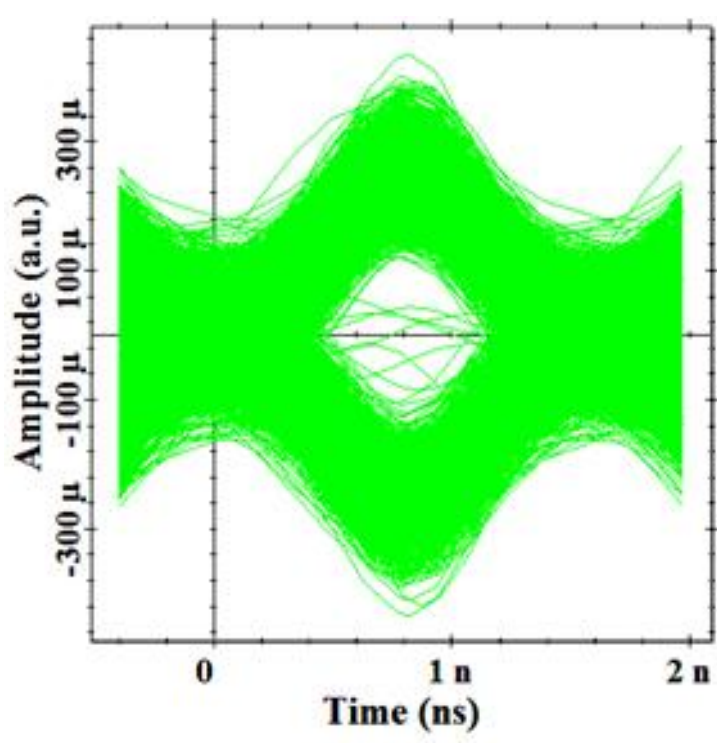

(a)

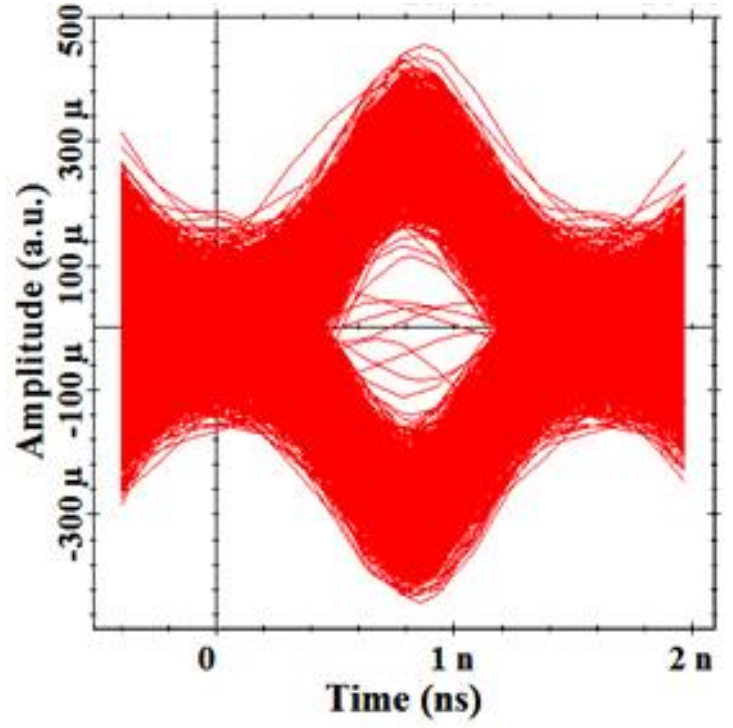

(b)

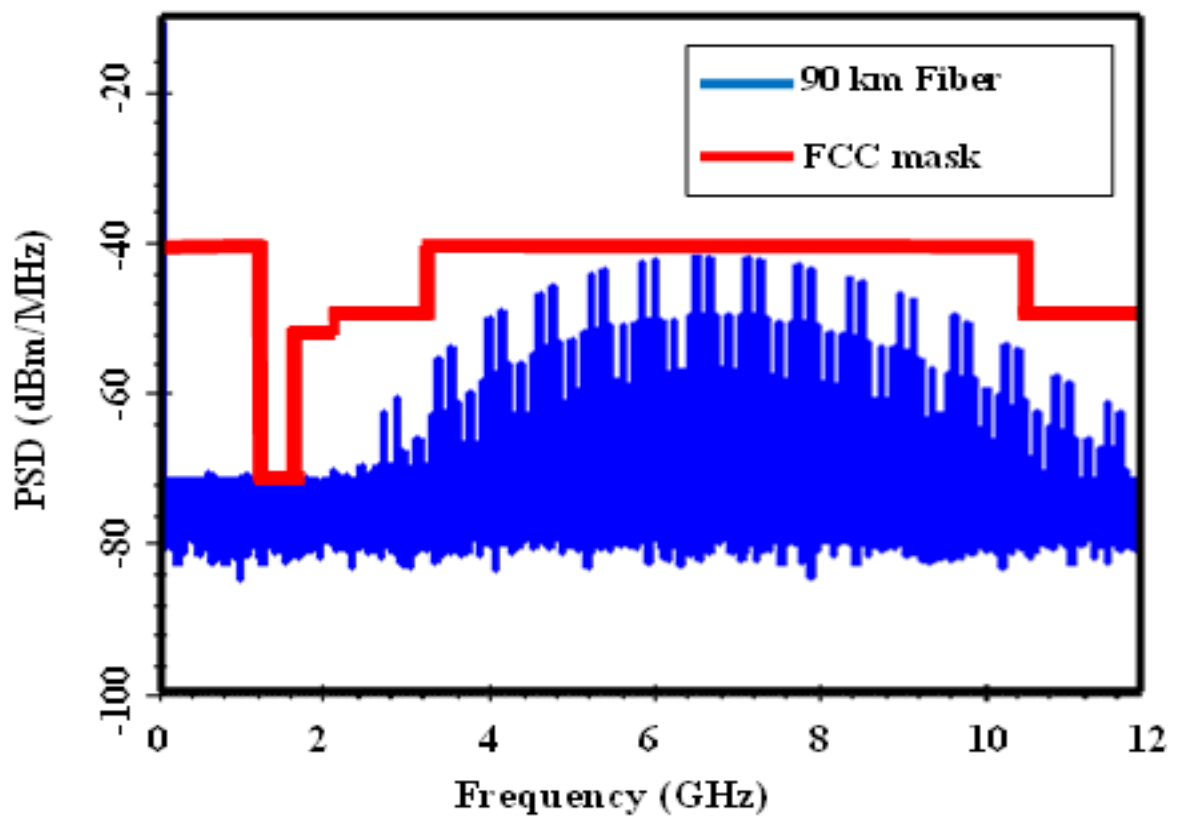

(c)

Fig. 12: Characteristics of the received signal after transmission over $90 \mathrm{~km} \mathrm{SMF}$ fiber for $625 \mathrm{Mb} / \mathrm{s} 5^{\text {th }}-$ order derivative Gaussian BPM system. (a) Eye diagram when DCF is not used. (b) Eye diagram when DCF is used. (c) Power spectrum density of the transmitted RF signal when DCF is used. 
Investigating the results in Table 2 and Figs 9-12 reveals the following findings

(i) The PSD of the transmitted RF signal associated with $5^{\text {th }}$-order derivative Gaussian system lies perfectly within FCC mask and characterized by high attenuated low frequency contents.

(ii) For a given received BER, monocycle system yields longer transmission link as compared with $5^{\text {th }}$-order derivative Gaussian system. At $\mathrm{BER}=10^{-9}$, the maximum allowable transmission length is reduced by $57 / 77.5=0.74$ and $90 / 107.25=0.84$ for OOK and BPM, respectively, when $5^{\text {th }}$-order Gaussian system are used to replace the monocycle system.

(iii) A slightly wider optical bandpass filter can be used to enhance the performance of the $5^{\text {th }}$-order Gaussian system as compared with monocycle system. Using $24 \mathrm{GHz}$ bandwidth filter in the $5^{\text {th }}$-order derivative Gaussian system will enhance the BER from $10^{-9}$ to $9.7 \times 10^{-11}$ and from $10^{-9}$ to $7.1 \times 10^{-11}$ in OOK and BPM formats, respectively.

\section{4- CONCLUSIONS}

Transmission performance of $625 \mathrm{Mb} / \mathrm{s}$ IR-UWB signals over optical fiber link incorporating SMF, DCF, and optical amplifiers has been investigated. The simulation results reveal that longer transmission distance can be achieved by using monocycle BPM. To achieve a received BER less than $10^{-9}$, the maximum transmission distance is $93 \mathrm{~km}$ and $128 \mathrm{~km}$ for monocycle system operating with OOK and BPM modulation formats, respectively. These values are to be compared with 68 and $108 \mathrm{~km}$ for $5^{\text {th }}$-order derivative Gaussian system operating with OOK and BPM modulation formats, respectively.

\section{5- REFERENCES}

[1] S. T. Abraha, C. Okonkwo, P. A. Gamage, E. Tangdiongga, and T. Koonen, "Routing of power efficient IR-UWB wireless and wired services for in-building network applications," Journal of Lightwave Technology, Vol. 30, No. 11, PP. 1651-1663, June, 2012.

[2] H. Yazdani, A. M. Rabiei, and N. C. Beaulieu, "On the benefits of MAI-plus-noise whitening in TH-BPSK IR-UWB systems," IEEE Transaction on Wireless Communications, Vol. 13, No. 7, PP. 3690-3700, July, 2014.

[3] X. Yu, T. B. Gibbon, R. Rodes, T. T. Pham, and I. T. Monroy, "System wide implementation of photonically generated impulse radio ultra-wideband for gigabit fiber-wireless access," Journal of Lightwave Technology, Vol. 31, No. 2, PP. 264-275, January, 2013.

[4] M. Ran, B. I. Lembrikov, and Y. Ben Ezra, "Ultra-wideband radio-over-optical fiber concepts, technologies and applications," IEEE Photonics Journal, Vol. 2, No. 1, PP. 36-84, February, 2010.

[5] L. Wang, C. H. Heng, and Y. Lian, "A sub-GHz mostly digital impulse radio UWB transceiver for wireless body sensor networks," IEEE Journal on Emerging and Selected Topics in Circuits and Systems, Vol. 4, No. 3, PP. 344-353, September, 2014.

[6] S. Ji, S. Lee and J. Kim," Efficient hybrid modulation with phase-directed pulse position estimation for UWB-IR systems, " IEEE Transaction on Communications, Vol. 61, No. 3, PP. 1171-1177, March, 2013.

[7] S. Kubota, A. Toya, T. Sugitani, and T. Kikkawa, "5-Gb/s and 10-GHz center-frequency Gaussian monocycle pulse transmission using 65-nm logic CMOS with on-chip dipole antenna and high-k interposer," IEEE Transaction on Components, Packing, and Manufacturing Technology, Vol. 4, No. 7, PP. 1193-1200, July, 2014.

[8] H. Ding, W. Liu, X. Huang, and L. Zheng, " First path detection using rank test in IR-UWB ranging with energy detection receiver under harsh environments," IEEE Communications Letters, Vol. 17, No. 4, PP. 761-764, April, 2013.

[9] M. Z. Dooghabadi, H. A. Hjortland, Ø. Næss, K. K. Lee, and T. S. Lande, "An IR-UWB transmitter for ranging systems," IEEE Transaction on Circuits and Systems-II: Express Brief, Vol. 60, No. 11, PP. 721-725, November, 2013.

[10] P. Carbone, A. Cazzorla, P. Ferrari, A. Flammini, A. Moschitta, S. Rinaldi, T. Sauter, and E.Sisinni, "Low complexity UWB radios for precise wireless sensor network synchronization," IEEE Transaction on Instrumentation and Measurements, Vol. 62, No. 9, PP. 2538-2548, September, 2013.

[11] 10- S. V. M. Moghtadaei, A. F. Ahmady, A. Z. Nezhad, and W. A. Serdijn, "A 90 nm-CMOS IR-UWB BPSK transmitter with spectrum tunability to improve peaceful UWB-narrowband coexistence," IEEE Transaction on Circuits and Systems—I: Regular Papers, Vol. 61, No. 6, PP. 1836-1848, June, 2014.

[12] M. Shen, Y. Z. Yin, H. Jiang, T. Tian, and J. H. Mikkelsen, "A 3-10 GHz IR-UWB CMOS pulse generator with 6 $\mathrm{mW}$ peak power dissipation using a slow-charge fast-discharge technique," IEEE Microwave and Wireless Components Letters, Vol. 24, No. 9, PP. 634-636, September, 2014. 
[13] B. Vigraham, and P.R. Kinget, "A self-duty-cycled and synchronized UWB pulse-radio receiver SoC with automatic threshold-recovery based demodulation," IEEE Journal of Solid-State Circuits, Vol. 49, No. 3, PP. 581 594, March, 2014.

[14] Z. Xu, H. Nie, Z. Chen, H. Khani, Weidong Xiang, and L. Yu, " On the nonlinear teager-kaiser operator for energy detection based impulse radio UWB receivers," IEEE Transaction on Wireless Communications, Vol. 13, No. 5, PP. 2955-2965, May, 2014.

[15] P. Li, H. Chen, M. Chen, and S. Xie, "Gigabit/s photonic generation, modulation, and transmission for a reconfigurable impulse radio UWB over fiber system," IEEE Photonics Journal, Vol. 4, No. 3, PP. 805-816, June, 2012.

[16] W. Liu, T. Shao, and J. Yao, "Ultra wideband and $60-\mathrm{GHz}$ generation and transmission over a wavelength division multiplexing-passive optical network," Journal of Optical Communication and Networks, Vol. 5, No. 9, PP. 1076-1082, September, 2013.

[17] P. Li, H. Chen, X. Wang, H. Yu, M. Chen, and S. Xie, "Photonic generation and transmission of 2-Gbit/s powerefficient IR-UWB signals employing an electro-optic phase modulator, " IEEE Photonics Technology Letters, Vol. 25, No. 2, PP. 144-146, January, 2013.

[18] R. Llorente, M. Beltran, and M. Morant, "UWB-over-fibre: Technology, performance and next-generation applications," Ultra Wideband Communications: Novel Trends-System, Architecture and Implementation, 2011, ISBN: 978-953-307-461-0, InTech.

[19] S. Pan, and J. Yao, "UWB-over-fiber communications: modulation and transmission," Journal of Lightwave Technology, Vol. 28, No. 16, PP. 2445-2455, August, 2010.

[20] T. T. Pham, X. Yu, T. B. Gibbon, L. Dittmann, and I.T. Monroy, "A WDM-PON-compatible system for simultaneous distribution of gigabit baseband and wireless ultrawideband services with flexible bandwidth allocation," IEEE Photonics Journal, Vol. 3, No. 1, PP. 13-19, February, 2011.

[21] J. E. Kadum and R. S. Fyath, "Transmission performance investigation of multi IR-UWB signals over DWDM communication system," International Journal of Computers and Technology, send for publication.

[22] J. E. Kadum and R. S. Fyath, "Integration of IR-UWB Services into Single- and Multi-Channel Optical Coherent OFDM Network," International Journal of Computers and Technology, send for publication. 


\section{Author Biography}

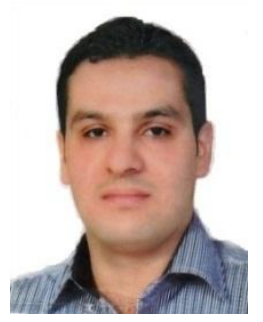

Jaffar Emad Kadum was born in Baghdad, Iraq, in 1986. He received the B.Sc. degree in Electronic and Communications Engineering from Alnahrain University, Iraq, in 2008. Currently, he is working toward the M.Sc. degree in Electronic and Communications Engineering at Alnahrain University. His research interests include ultra wideband over fiber, radio over fiber, microwave photonics and Optical communications systems.

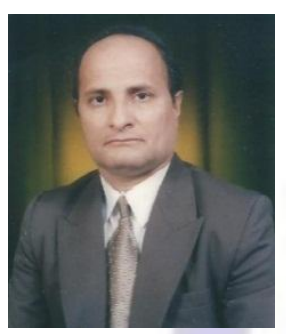

Raad Sami Fyath was born in Maysan, Iraq, in 1954. He received the B.Sc. degree in Electrical Engineering from the University of Basrah, Iraq, in 1976, the M.Sc. degree in Electronics and Communications Engineering from the University of Baghdad, Iraq, in 1987, and the PhD degree in Electronics Engineering from University of Wales-Bangor, UK, in 1990. Currently, he is a professor of electronics and communications engineering at the College of Engineering, Alnahrain University, Baghdad, Iraq. His research interests include Optical and wireless communications, Optoelectronics, and Nanophotonics. He published more than 100 papers in different scientific journals and conference proceedings. 